\title{
O TERRITÓRIO E SUAS DIMENSÕES POLÍTICA, CULTURAL E ECONÔMICA: UMA ANÁLISE INTEGRADORA-HÍBRIDA DAS PRÁTICAS DE TERRITORIALIZAÇÃO ${ }^{1}$
}

\author{
Marcos Leandro Mondardo 2
}

\section{Resumo}

Este trabalho tem por objetivo compreender aspectos do território no Sudoeste do Paraná, a partir, de três dimensões: política, cultural e econômica. Busca-se, compreender estas dimensões aliado a migração e o trabalho, características intrínsecas historicamente ao recorte territorial analisado. Entendemos que a partir de 1940, com a migração de gaúchos e catarinenses para o Sudoeste do Paraná ocorre, uma dominação e apropriação do território vinculada a um modo de vida próprio da cultura italiana e alemã principalmente. No desenrolar da produção territorial, criam-se elementos políticos e econômicos que moldam a configuração do território, direcionando as ações dos sujeitos para realização de certos projetos da classe dominante. Em outros aspectos são criados elementos simbólicos para legitimar uma determinada ordem para um determinado sentido de vida; cria-se um pertencimento que atribui uma identidade para os migrantes que se reterritorializam no Sudoeste do Paraná. A classe dominante produtora de simbolismos, também atua na forma da exploração dos indivíduos que servem de mão-de-obra na agricultura e na indústria para a (re)produção do capital. Ocorre uma segregação de sujeitos que são fixados territorialmente em partes estratégicas do território.

Palavras chave: Sudoeste do Paraná; Migração; Trabalho; Território; Identidade.

\section{Abstract}

This work has for objective to understand aspects of the territory in the Southwest of Paraná, to leave, of three dimensions: politics, cultural and economic. It is looked for, to understand these dimensions ally the migration and the work, intrinsic characteristics

\footnotetext{
${ }^{1} \mathrm{O}$ presente trabalho faz parte de projeto de pesquisa intitulado: O território e as migrações no Sudoeste do Paraná, desenvolvido junto ao Programa de Pós-Graduação em Geografia da Universidade Federal da Grande Dourados - UFGD, que contou com apoio financeiro da CAPES

${ }^{2}$ Mestrando em Geografia pelo Programa de Pós-Graduação da Universidade Federal da Grande Dourados UFGD; Bolsista CAPES; E-mail: marcosmondardo@yahoo.com.br
} 
historically to the analyzed territorial cutting. We understood that starting from 1940, with the gaúchos migration and catarinenses for the Southwest of Paraná, it happens a dominance and appropriation of the territory linked mainly to an own life way of the Italian and German culture. In uncoiling of the territorial production, political and economic elements are created that they mold the configuration of the territory, addressing the actions of the subjects for accomplishment of certain projects of the dominant class. In another aspects symbolic elements are created to legitimate a certain order for a certain life sense; a belonging is created that attributes an identity for the migrants that if reterritoriallyty in the Southwest of Paraná. The dominant class producing of symbolisms, also acts in the form of the individuals' exploration that you/they serve as labor in the agriculture and in the industry for the (re)production of the capital. A segregation of subjects that territorially is fastened in strategic parts of the territory happens.

Keywords: Southwest of Paraná; Migration; Work; Territory; Identity.

\section{Introdução}

O território, imerso em relações de dominação e/ou de apropriação sociedadeespaço, desdobra-se ao longo de um continuum que vai da dominação políticoeconômica mais "concreta" e "funcional" à apropriação mais subjetiva e/ou “cultural-simbólica” (HAESBAERT, 2004, pp. 95-96).

A migração no Sudoeste do Paraná é um elemento importante para a (re)produção histórica do território. Migrantes, principalmente gaúchos e catarinenses se deslocaram para dominar, apropriar e transformar o território ${ }^{3}$. Através do trabalho destes sujeitos, com o passar do tempo, ocorreu uma transformação intensa resultando na constituição de infraestruturas rurais e urbanas, contribuindo, assim, para o escoamento de considerável produção de alimentos. A partir da migração o território passou a ser usado e dominado/apropriado de forma intensa, resultando em uma modificação das paisagens e na construção de simbolismos que, moldaram a identidade territorial desses migrantes. Hábitos, modos de ver e fazer o "mundo" foram sendo reterritorializados pelos migrantes através de novas relações sociedadenatureza.

\footnotetext{
${ }^{3}$ É claro que antes da chegada destes migrantes gaúchos e catarinenses vivia, no Sudoeste do Paraná, uma população denominada genericamente de caboclos, aos quais, foge do objetivo desse trabalho as relações desenvolvidas entre estes sujeitos e os migrantes que aqui analisamos.
} 
Assim, este artigo pretende compreender através do processo histórico as "marcas" impregnadas no território, sobretudo, a partir de 1940, com a migração de gaúchos e catarinenses. Apontamos, sobretudo, para elementos da migração relacionados à dinâmica da transformação do território pelo trabalho dos migrantes. Pretendemos analisar, assim, o papel das migrações na dominação e apropriação do território a partir de três dimensões e/ou perspectivas: 1. jurídico-política - onde o território é visto como um espaço delimitado e controlado sobre o qual se exerce um determinado poder, especialmente o de caráter estatal; 2. cultural - que prioriza sua dimensão simbólica e subjetiva; o território visto fundamentalmente como produto da apropriação feita através do imaginário e/ou da identidade social sobre o espaço; 3. econômica - que destaca o território em sua perspectiva material, concreta, como produto espacial do embate entre classes sociais e da relação capitaltrabalho (HAESBAERT, 1997, p. 39-40).

Nesse sentido, o referido escopo está fundamentado em pesquisas que vêm sendo desenvolvidas desde o ano de 2004, as quais têm dentre outros objetivos compreender a migração para o Sudoeste do Paraná de gaúchos e catarinenses, buscando apreender os diversos modos de apropriação, dominação e/ou uso do território. Para desenvolver a análise, procuramos estudos sobre o Sudoeste do Paraná e, também, autores que desenvolveram em suas pesquisas, conceitos de migração, trabalho, território e identidade.

$\mathrm{Na}$ primeira parte do texto discutimos alguns elementos conceituais referentes à migração, trabalho e território; num segundo momento, buscamos entender o processo da migração e do trabalho em relação aos diferentes modos de uso do território, isto é, analisamos as diferentes "marcas" impregnadas pelos migrantes no território; e, por fim, apontamos os resultados, ainda parciais, de nossa pesquisa referente à reflexão aqui elaborada.

\section{Pressupostos teóricos: migração, trabalho e território}

A migração de gaúchos e catarinenses para o Sudoeste do Paraná está ligada intimamente ao processo de reprodução da força de trabalho (SAQUET, 2006), que resultou na apropriação, dominação e, deste modo, na transformação do território. Entendemos, assim, que através da migração ocorre a dominação e a apropriação de um território que produz, através do tempo, um modo de vida singular através das práticas políticas, culturais e econômicas dos migrantes inseridas, no território, através do processo de reterritorialização. 
Nesse sentido, é basilar discutirmos, mesmo que minimamente, alguns elementos pertinentes sobre a dinâmica migratória. De acordo com Becker (1997, p. 323), a migração pode ser entendida "como mobilidade espacial da população. Sendo um mecanismo de deslocamento populacional, reflete mudanças nas relações entre as pessoas (relações de produção) e entre essas e o seu meio ambiente físico". Nesta perspectiva o deslocamento de indivíduos reflete alterações nas relações de produção e conseqüentemente alterações na reprodução do território.

Em outra vertente, Salim (1992, p.125) entende que a migração é elemento estratégico para a concentração espacial na reprodução do capital: "A migração seria resultado e condição estratégica do desenvolvimento do capital, como também elemento importante de sua concentração espacial". Ainda, segundo Salim (1992, p. 126), o “Migrante é concebido simultaneamente como integrante do exército industrial da ativa e da reserva e, via de regra, resulta de transformações sociais de produção nas áreas de origem”.

Também, muito próximo dessa perspectiva, Singer (1998) afirma que a mobilidade no capitalismo é uma "mobilidade forçada" em decorrência, de um lado, da introdução de relações de produção capitalistas que acarretam a expropriação de camponeses, além da decadência ou atraso tecnológico em determinadas áreas, provocando a carência de trabalho, e, de outro, da necessidade do trabalhador inserir-se em novas frentes.

Segundo o autor, os fatores de "expulsão" de camponeses são importantes no movimento da sociedade:

\footnotetext{
Os fatores de expulsão que levam às migrações são de duas ordens: fatores de mudança, que decorrem da introdução de relações de produção capitalistas nestas áreas, a qual acarreta a expropriação de camponeses, a expulsão de agregados, parceiros e outros agricultores não proprietários, tendo por objetivo o aumento da produtividade do trabalho e a conseqüente redução do nível de emprego (....) e fatores de estagnação, que se manifestam sob a forma de uma crescente pressão populacional sobre uma disponibilidade de áreas cultiváveis física de terra aproveitável como pela monopolização de grande parte da mesma pelos grandes proprietários (SINGER, 1998, p. 37).
}

Portanto, no deslocamento de gaúchos e catarinenses para o Sudoeste do Paraná a partir da perspectiva da mobilidade da força de trabalho, podemos considerar que o trabalhador é colocado à disposição do capital e se vê "forçado" a migrar, pois, a única mercadoria que possui é a própria força de trabalho. Nesse processo, os trabalhadores vendem sua própria força de trabalho para sua sobrevivência e, com isso, tornam-se móveis para 
acompanhar o movimento de (expansão) do capital e, assim, para o migrante reproduzir e sobreviver.

Contudo, existe no processo migratório, além das causas estruturais como os autores apontam, os motivos individuais, da interiorização e, portanto, da subjetividade dos sujeitos que se deslocam para outros lugares. Nessa perspectiva, devemos considerar que:

\begin{abstract}
As causas estruturais são determinadas pela estrutura da sociedade, enquanto os motivos subjetivos refletem a interiorização, pelos agentes sociais, de suas condições sociais de existência: essas duas dimensões são vividas simultaneamente pelos grupos sociais em questão, sendo distinguíveis apenas a nível analítico (TAVARES DOS SANTOS, 1993, p. 14).
\end{abstract}

Assim, a busca pela dialética entre elementos estruturais e individuais na migração se torna importante para a análise e compreensão mais aprofundada do fenômeno.

Sendo assim, buscamos entender, a partir das migrações, a perspectiva do trabalho enquanto elemento atuante e modelador das relações de produção, de vida, de sintonia com as transformações territoriais. Segundo Santos (1988, p. 87), "O trabalho é a aplicação, sobre a natureza, da energia do homem, diretamente ou como prolongamento do seu corpo através de dispositivos mecânicos, no propósito de reproduzir a sua vida e a do grupo". Ainda, para o autor, "o homem é o único que reflete sobre a realização de seu trabalho", que pensa e organiza seu processo produtivo, buscando prever o resultado de seu esforço na transformação da matéria. Assim, "Na sua relação com a natureza, o homem não tem uma atitude de repetição, mas sim de invenção" (SANTOS, 1988, p. 87).

Também, na perspectiva da transformação da natureza, de acordo com Marx (1985, p.149), "o trabalho é um processo entre o homem e a natureza, um processo em que o homem, por sua própria ação, media, regula e controla seu metabolismo com a natureza". Segundo Marx, ao mesmo tempo em que o homem transforma a matéria da natureza, ele transforma a ele mesmo. "No processo de trabalho a atividade do homem efetua, portanto, mediante o meio de trabalho, uma transformação do objeto do trabalho, pretendida desde o princípio" (MARX, 1985, p. 151).

Nesses apontamentos, o trabalho é uma atividade orientada para um fim, isto é, para produzir valores de uso e valores de troca para dominação/apropriação do território e, também, para a satisfação das necessidades e dos desejos humanos. Nesse sentido, o território vai sendo moldado através das políticas, que resultam nas ações pelo trabalho dos sujeitos que 
produzem seus territórios propriamente ditos, o território do abrigo (a casa), o território do trabalho, o território da festa etc., para a reprodução de um modo de vida "específico".

Nesse contexto, a relevância do território para atuação dos sujeitos que migraram se torna fundamental. Estes migrantes fixam-se no território para a produção de um modo de vida que está em constante transformação. (Trans)formam-se os indivíduos, (trans)forma-se o território. Assim, é importante compreendermos o que é território, mesmo que já anteriormente, apresentamos alguns elementos fundantes e ativos que, iremos desenvolver aqui. Nesse sentido, segundo Santos e Silveira (2006, p. 19) "Por território entende-se geralmente a extensão apropriada e usada". Para Santos (1996, p. 15) "É o uso do território, e não o território em si mesmo, que faz dele objeto da análise social. Trata-se de uma forma impura, um híbrido (...). O que ele tem de permanente é ser o nosso quadro de vida”.

A partir disso, entendemos que é pelo uso a partir do trabalho dos sujeitos que se dá a apropriação e transformação do território através do(s) tempo(s). Os indivíduos se apropriam e dominam o território através do trabalho (em sentido amplo) para sua sobrevivência, reprodução e, conseqüentemente, constituição das relações de poder, das relações de classes. Segundo Santos (1996, p. 20), “O que interessa discutir é, então, o território usado, sinônimo de espaço geográfico”. Assim, “(...) o território usado são objetos e ações, sinônimo de espaço humano, espaço habitado" (p. 16).

Outra perspectiva é aquela que busca entender o território a partir das relações de poder, em um entrelaçamento concomitante do poder simbólico e do poder político. Nessa vertente:

O território envolve sempre, ao mesmo tempo (...), uma dimensão simbólica, cultural, por meio de uma identidade territorial atribuída pelos grupos sociais, como forma de controle simbólico sobre o espaço onde vivem (sendo também, portanto, uma forma de apropriação), e uma dimensão mais concreta, de caráter políticodisciplinar: a apropriação e ordenação do espaço como forma de domínio e disciplinarização dos indivíduos (HAESBAERT, 1997, p. 42).

Nesse contexto, ainda:

(...) o território deve ser visto na perspectiva não apenas de um domínio ou controle politicamente estruturado, mas também de apropriação que incorpora uma dimensão simbólica, identitária e, porque não dizer, dependendo do grupo ou classe social a que estivermos nos referindo, afetiva (HAESBAERT, 1997, 41, grifo do autor).

Portanto, o território apresenta características simbólicas vinculadas ao espaço onde vivem os sujeitos - em nosso caso a territorialidade dos migrantes que, fizeram e fazem o 
território - e, também, das características políticas, vinculadas à dominação do território e a sua (re)produção pelo controle político do mesmo.

Assim, na tentativa de apreender as relações no território a partir das migrações e do trabalho, pretendemos refletir sobre elementos pertinentes ao desenvolvimento e a transformação do Sudoeste do Paraná, historicamente.

\section{O território do sudoeste do Paraná e às dimensões política, cultural e econômica: uma perspectiva integradora-híbrida das práticas de territorialização}

A partir de 1940, inicia-se o processo da chamada "ocupação efetiva" do Sudoeste do Paraná. Esse movimento de colonização está fundamentalmente ligado à mobilidade espacial da força de trabalho, em função do deslocamento de descendentes de italianos e alemães oriundos, do Rio Grande do Sul e de Santa Catarina. Ocorre, nesse sentido, um desdobramento social de sujeitos que se territorializaram na forma de pequenas propriedades familiares, artesanais e mercantis, materializando, assim, suas relações advindas, principalmente, do Rio Grande do Sul desde o século XIX, para o Sudoeste paranaense (SAQUET, 2006, p. 161).

As colonizações alemã e italiana geraram, no Rio Grande do Sul, um excedente populacional, em função principalmente do excesso da fragmentação das pequenas propriedades rurais, resultante da herança familiar e da pressão demográfica sobre a estrutura fundiária e, aliando a isso, pela crise da indústria gaúcha incapaz de absorver esta mão-deobra oriunda da zona rural (PADIS, 1981). Por isso, esse excedente populacional gerado é condicionado a migrar para o Oeste de Santa Catarina, até os anos de 1930 e, para o Sudoeste e Oeste do Paraná, a partir dos anos de 1940.

Assim, a população que no início do século XX no Sudoeste do Paraná era constituída por 3.000 habitantes e, de 1900 a 1920 era formada por 6.000 habitantes (WACHOWICZ, 1987, p. 55-58), tem a partir de 1940 um acréscimo populacional grande e rápido. Nestes aspectos, buscando diminuir a pressão dos pequenos agricultores no campo do Rio Grande do Sul e, também, ocupar o até então território "pouco habitado" do Sudoeste do Paraná, o Presidente Getúlio Vargas decide criar, em 1943, a Colônia Agrícola Nacional General Osório (CANGO), que subsidiou e impulsionou a chegada de gaúchos e catarinenses ao território do Sudoeste paranaense.

De acordo com Saquet (2006, p. 162), a migração gaúcha e catarinense estava intimamente ligada aos interesses do Estado e dos agentes do capital. Pretendia-se 
estrategicamente ocupar/colonizar as áreas de fronteira e, com isso, aumentar a produção de alimentos a baixo preço para o mercado interno. Esse processo de reterritorialização de migrantes estava vinculado às pequenas propriedades rurais, na policultura e no trabalho familiar. Buscou-se estimular o aumento de excedentes mercantis, ocorrendo, a valorização das terras e, a subordinação de produtores agrícolas diretos ao comércio. Criou-se, nesse sentido, redes de comunicação e circulação para ligar as cidades que surgiam, ajudando no seu crescimento, tendo conseqüentemente, logo, a expansão da urbanização no território. Essas mudanças transformaram a estrutura territorial do Sudoeste do Paraná, voltada, a partir de então, para a "forma" criada e materializada pelo Estado e pelos agentes do capital.

Esse fluxo migratório para o Sudoeste do Paraná dirigido pelo Estado, foi chamado de frente pioneira. Para Martins (1997, p. 153), frente pioneira é mais do que o deslocamento da população sobre territórios novos. Ela é caracterizada também pela "situação espacial e social que convida ou induz à modernização, à formulação de novas concepções de vida, à mudança social". Essa concepção de frente pioneira explicita a criação do território novo, da nova sociabilidade fundada no mercado e na contratualidade das relações sociais.

Nesse contexto, temos a ação de controle e dominação do território pelo Estado. Este atua no sentido de organizar o território para os migrantes no Sudoeste do Paraná para um devido fim, isto é, a reprodução ampliada do capital. Segundo Raffestin (1993, p. 39), o Estado é uma organização da sociedade: “a maior das organizações é o Estado, ele não é a única: as organizações canalizam, bloqueiam, controlam, ou seja, domesticam as forças sociais”. Nesse sentido, as organizações:

\begin{abstract}
(...) "canalizam" quer dizer que obrigam a tomada de linhas de função determinada, quer se trate do espaço, concreto, geográfico, quer do espaço abstrato social; "bloqueiam" significa que agem sobre as disjunções, para isolar e dominar; "controlam", ou seja, têm tudo ou procuram ter tudo sob o olhar, criam um "espaço de visibilidade no qual o poder vê, sem ser visto". (...) Domesticar é portanto encerrar numa rede, numa malha em que todas as partes estão debaixo do olhar. (...) O Estado só recorta o espaço em malhas mais ou menos cerradas por um única razão: deve encontrar a "malha" mais adequada para, levando em consideração os seus meios, "ver" o melhor possível. Só abre certas vias de comunicação e traça certas fronteiras por essa razão (RAFFESTIN, 1993, 39, [grifos nossos])
\end{abstract}

Nesse contexto, podemos entender que o Estado como uma organização da sociedade que utiliza os espaços de "fronteira" para dominação e apropriação de recursos naturais e humanos, que se expressa através do poder": "O poder visa o controle e a dominação sobre os

\footnotetext{
${ }^{4}$ Entendemos, apoiados em Foucault (1985, p. 14), que o poder é uma relação, e que “(...) os poderes não estão localizados em nenhum ponto específico da estrutura social. Funcionam como uma rede de dispositivos ou
} 
homens e sobre as coisas. (...) a população, o território e os recursos" (RAFFESTIN, 1993, p. $58)$.

Assim, sobre o poder e território, apoiados em Raffestin (1993), podemos dizer que no Sudoeste do Paraná o Estado escolheu a imigração indicando "a vontade de economizar o tempo ou de valorizá-lo, o que dá no mesmo" (p. 78). Nesse contexto, podemos entender a manobra de atuação do Estado para dominação e organização do território. Raffestin (1993, p. 88) afirma que com a migração as organizações, adotam diversas estratégias para aumentar o movimento ou, ao contrário, para freá-lo. As políticas migratórias são de extrema importância porque controlam e administram os fluxos para organização que redundam na dominação do território.

Portanto, com a ação de controle e organização do Estado, a CANGO foi criada pelo Governo Vargas para ajudar, dentre outras coisas, a formar os primeiros povoados para a apropriação e produção territorial. Construíram-se inicialmente igrejas, casas comerciais, trouxeram-se instrumentos para a produção agrícola etc. Conforme Martins (1986), em 1951, a vila Marrecas (atual município de Francisco Beltrão) era formada por 350 casas residenciais, hospital, igreja, escola, farmácia, 25 estabelecimentos comerciais, 2 ferrarias, 2 oficinas mecânicas, 5 marcenarias, 2 moinhos, 2 alfaiatarias, 3 hotéis e 1 fábrica de refrigerantes. Segundo Saquet (2006, p. 163), “a principal via de ligação com outros lugares passava por Pato Branco, Clevelândia, Palmas até União da Vitória”. Constituíam-se, assim, as redes de circulação e comunicação que moldavam a formação territorial.

Outro aspecto importante é que, com o surgimento de inúmeros centros urbanos se deslocaram outros sujeitos, além de agricultores para o Sudoeste do Paraná. Nestes termos:

(...) essas rápidas transformações, especialmente o crescimento dos núcleos urbanos e a criação de novos com subseqüente multiplicação da demanda dos serviços, provocarão diversidade na origem dos migrantes. Assim é que (...) virão para o sudoeste paranaense não só agricultores, mas habitantes das cidades gaúchas - e de outros pontos do país - cuja capacitação profissional ia do pequeno comerciante, prestador de serviços, até os profissionais liberais, de formação universitária (PADIS, 1981, p. 172).

mecanismo a que nada ou ninguém escapa, a que não existe exterior possível, limites ou fronteiras. (...) Rigorosamente falando, o poder não existe; existem práticas ou relações de poder. $\mathrm{O}$ que significa dizer que o poder é algo que se exerce, que se efetua, que funciona. E que funciona como uma maquinaria, como uma máquina social que não está situada em um lugar privilegiado ou exclusivo, mas se dissemina por toda a estrutura social. Não é um objeto, uma coisa, mas uma relação". Nessas relações de poder, Raffestin (1993, p. 75), afirma que "Toda relação de poder coisifica o ser humano: este 'não é', ele é qualquer coisa que se 'tem', que não se tem, que se terá ou que não se terá". 
Nestes aspectos, ao mesmo tempo em que a zona rural do Sudoeste do Paraná foi sendo transformada, novos atores foram chegando para atuar e/ou criar novos elementos para uma maior complexificação do território, que buscava atender uma maior demanda de novas funções que se especializavam e se espacializavam nas cidades. Novas necessidades, novos sujeitos e, com isso o território teve sua estrutura alterada. À medida que no território surgiam novas possibilidades de inserção social para determinados indivíduos, estes migravam em busca dessa inserção pelo trabalho no Sudoeste do Paraná.

Também, com os migrantes se estabeleceram no território simbolismos vinculados, sobretudo, à cultura gaúcha, onde se criou uma identidade do Sudoestino, do ser sujeito do Sudoeste do Paraná. Esta dimensão mais simbólica do território é apontada por Haesbaert (1997), em que o território é visto mais pela subjetividade dos indivíduos que compõe o território; o território é visto como produto do imaginário local de apropriação de culturas, de modos de ver e fazer o lugar; da identidade social que se territorializa no espaço geográfico. Neste sentido:

Os símbolos são os instrumentos por excelência da integração social: enquanto instrumentos de conhecimento e de comunicação (...) eles tornam possível o consensus acerca do sentido do mundo social que contribui fundamentalmente para a reprodução da ordem social: a integração lógica é a condição da integração moral (BOURDIEU, 1998, p. 10, [grifo do autor]).

Assim, os símbolos criados podem ser vinculados ao sentido de pertencimento para criar a identidade dos indivíduos do Sudoeste do Paraná. Denotam uma integração social dos sujeitos que formam e fazem o território. Como apontado por Bourdieu (1998), estes símbolos estabelecem uma ordem social, ocorrendo uma integração lógica e moral entre os indivíduos que transformam e deixam suas "marcas" no território.

Nestes termos, vários elementos simbólicos são criados para retratar uma dada forma de ocupação no território. No Sudoeste do Paraná, vários monumentos são erguidos vinculados aos "pioneiros", vários costumes tradicionais de integração entre os sujeitos são mantidos, principalmente a cultural gaúcha como o chimarrão, as roupas, o linguajar regional etc. Assim, são atribuídos uma série de elementos simbólicos que "marcam" a identificação do sujeito com o território. Nesse sentido:

Uma identidade de grupo é muito mais do que um rótulo ou do que uma designação categórica. Ela inclui tanto um sentido de pertencer a um grupo como também as atitudes e os sentimentos que acompanham ser membro do grupo (...) Uma identidade de um grupo provê uma perspectiva internalizada a partir da qual o indivíduo se vê a si mesmo e aos outros (PHINNEY, 2004, p. 49). 
Um elemento importante vinculado à identidade é a música. Esta faz parte de um contexto cultural do território do Sudoeste do Paraná. Mesclam-se ritmos da música gaúcha com o ritmo denominado "bandinhas" (oriundos sobretudo dos estados do Rio Grande do Sul e de Santa Catarina). São estes elementos simbólicos, visíveis e invisíveis, que atribuem significados singulares e constroem o imaginário do cidadão Sudoestino, do sujeito que cria, a partir do imaginário, representações de si próprio e de sujeitos de outros territórios, isto é, dos "outros".

Aliado a isso, temos a perspectiva do sujeito do Sudoeste do Paraná como trabalhador. Daquele indivíduo do trabalho que busca o "progresso" social aliado ao bem estar e ao conforto. É aquele que através do "trabalho consegue as coisas". Da busca pela melhor posição social. É pelo trabalho que o sujeito se mostra valioso, bem visto na sociedade do Sudoeste paranaense. As representações se dão através do imaginário da colonização do território. De migrantes que vieram para trabalhar, reproduzir e conquistar à ascensão social. A busca pelo ideário da riqueza, "do ser rico", “do estar bem na vida”. "É pelo trabalho que se conquista". "Do levantar cedo para lavorar", ou do levantar cedo para trabalhar na indústria, no comércio, na construção civil etc. Um ideário de progresso, do moderno, do novo que induz a busca pelo "futuro melhor"

Também, na perspectiva do simbolismo, segundo Saquet (2006, p. 181), a maioria das praças construídas e reconstruídas do Sudoeste do Paraná aparecerem como lugares simbólicos para o território. Lugares de encontro, de namoro, de bate-papo entre amigos etc. Contudo, isso não quer dizer que a inserção de novos elementos não estejam presentes, mesmo que em menor proporção, como os da informática e da internet. Contudo, as praças conservam elementos simbólicos que expressam e buscam constantemente reforçar e manter viva a história do território ${ }^{6}$. Busca-se re-produzir e re-forçar a identidade dos sujeitos. "Do amor ao lugar". "Do ser cidadão do Sudoeste do Paraná". "Do gostar de viver aqui!".

Por outro lado, apontando elementos de classes que compõe o Sudoeste do Paraná, temos a perspectiva econômica do território, em que, segundo Haesbaert (1997, p. 39-40), nessa dimensão é destacado no território, a materialização das ações dos indivíduos, sendo

\footnotetext{
${ }^{5}$ Também "A produção e a reprodução de representações encerram relações de poder: quem pode e quem não poder ser 'digno', através do trabalho" (GOETTERT, 2002, p. 283).

${ }^{6}$ É claro que "As diferentes classes e frações de classes estão envolvidas numa luta propriamente simbólica para imporem a definição do mundo social mais conforme aos seus interesses, e imporem o campo das tomadas de posições ideológicas reproduzindo em forma transfigurada o campo das posições sociais" (BOURDIEU, 1998, p. $11)$.
} 
estes resultados e/ou produto espacial do embate entre classes social e da relação capitaltrabalho.

Deste modo, sob a ótica econômica, o território do Sudoeste do Paraná apresenta elementos importantes para análise. Na zona rural, o que percebemos é que num primeiro momento de ocupação do território, os agricultores em sua maioria eram pequenos produtores que foram "dominados" pelos comerciantes, isto é, os agricultores na maioria das vezes financiavam suas plantações no comércio para pagar quando tivessem realizado a colheita. Assim, esse processo deixou o agricultor na maioria das vezes, "preso" ao comerciante e, com isso, boa parte do "lucro" do agricultor era canalizado para pagar as dívidas com o comércio.

Outro aspecto relevante é que, com o passar do tempo, várias indústrias começaram a adentrar no meio rural, adquirindo inúmeras propriedades de agricultores que se viram "obrigados" a migrarem do campo para a cidade. Essa proletarização dos agricultores aconteceu e acontece no Sudoeste do Paraná (MONDARDO, 2005 [2007]). Esse processo resulta em uma segregação dos migrantes nas cidades oriundos da zona rural. Estes sujeitos habitam bairros periféricos das cidades (principalmente em Francisco Beltrão, Pato Branco e Dois Vizinhos) se tornando, assim, mão-de-obra para as indústrias, localizadas, principalmente no entorno destes bairros periféricos. Há nitidamente um processo de proletarização do migrante, do campo para cidade, através do êxodo rural.

Segundo Saquet (2006), ocorre no Sudoeste do Paraná um processo de expansão de capital no campo, claro e disfarçadamente. Segundo o autor, as unidades da Sadia que atuam nos municípios de Francisco Beltrão e Dois Vizinhos, estão territorializadas na cidade e no campo. Ocorre um processo de integração contratual que vincula e subordina produtores familiares rurais através do mecanismo de preços diferenciados praticado no mercado. A empresa atua no sentido de manter ligado o produtor num sistema contratual em que os lotes da mercadoria (frangos e perus) são pagos normalmente por preços pré-estipulados, havendo, assim, uma exploração do pequeno produtor em frente a grande indústria. Neste contexto, "parte das principais estradas secundárias de Francisco Beltrão foram calçadas pela prefeitura municipal em virtude das exigências da Sadia para se instalar no município" (SAQUET, 2006, p. 174).

Neste contexto, como afirmou Raffestin (1993, p. 144), “O espaço é a 'prisão original', o território é a prisão que os homens constroem para si”, pois a produção do território do Sudoeste paranaense apresenta uma articulação territorial com a constituição de redes de comunicação e circulação que têm o papel contraditório de "libertar" e "aprisionar", 
ligando e desligando diferentes indivíduos no território, re-construído constantemente de acordo com os interesses da classe dominante, isto é, do capital, da política e da cultura.

\section{Considerações finais}

Buscamos refletir e demonstrar aqui os diferentes usos do território. Analisamos alguns elementos da (trans)formação territorial do Sudoeste do Paraná a partir de três dimensões do território: 1. jurídico-política; 2. cultural; e, 3. econômica. A partir daí, entendemos que através do tempo a migração teve fundamental importância para a construção e reconstrução de "marcas" no território. Do desenrolar da migração de gaúchos e catarinenses ocorre, um processo de apropriação e dominação do espaço, que através do trabalho destes sujeitos, vai sendo formado e "modelado" um território determinado por um específico modo de vida. Esse viver atribui uma territorialidade a estes indivíduos que criam representações do território Sudoeste do Paraná, gerando um pertencimento vinculado a uma identidade territorial. É criado um "amor" ao território, que vinculado a uma cultura “específica” que, desenvolve-se territorialmente por italianos e alemães, principalmente.

A cultura destes sujeitos impõe a caracterização e reprodução do território. As formas de produzir, criar e re-criar a vida são formadas por uma cultura própria criando um território específico. Elementos políticos constroem um direcionamento das ações dos indivíduos, mas que, também, os sujeitos conseguem, através de sua territorialidade, produzir seus elementos singulares, pertinentes e particulares de um tipo de vida apoiada na cultura italiana e alemã.

Quanto aos elementos simbólicos, estes são reconstruídos constantemente para manter uma ordem, um estilo, um status quo de vida para o estabelecimento de um determinado fim. Cria-se, principalmente pela classe dominante, um direcionamento da identidade dos sujeitos para legitimar interesses próprios desta classe.

Assim, a classe dominante (composta, pelos donos do comércio, das indústrias e pelos representantes do Estado), consegue no Sudoeste paranaense territorializar os indivíduos (resultantes do processo de expropriação do êxodo rural) principalmente nas cidades, de acordo com seus interesses contraditórios de reprodução do capital. Ocorre uma segregação nos espaços urbanos dos sujeitos oriundos, sobretudo da zona rural, servindo de mão-de-obra barata para as indústrias que se instalam e se reproduzem no território.

Nesse sentido, imbricam-se as dimensões econômicas, políticas e culturais para a produção e reprodução do território através, das relações produzidas pelos migrantes gaúchos 
e catarinenses sendo direcionados, pelos projetos e interesses da classe dominante que se expressa e materializa através das ações dos comerciantes, dos donos de indústrias e dos representantes do Estado que, direcionam e mobilizam determinados projetos de classe através, de símbolos, de idéias, de ações, de representações, de objetos etc. O território, desse modo, aparece sempre como um híbrido, como ressaltou Santos e Silveira (2006) e, portanto, é produto e resultado do concomitante entrelaçamento das dimensões econômicas, políticas e culturais como assinalou Haesbaert (2006), pois, as relações sociedade-natureza são complexas e dinâmicas, produzidas, a partir do uso, da apropriação e da dominação uma territorialização cotidiana multidimensional.

\section{Referências Bibliográficas}

BOURDIEU, Pierre. O poder simbólico. 2. ed. Lisboa; Rio de Janeiro: Bertrand Brasil, 1998.

BECKER, Olga Maria Schild. Mobilidade espacial da população: conceitos, tipologia, contextos. In: CASTRO, Iná Elias de; GOMES, Paulo César da Costa; CORRÊA, Roberto Lobato (orgs.). Explorações geográficas. Rio de Janeiro: Bertrand Brasil, 1997, pp. 319-367.

GOETTERT, Jones Dari. Aos "vadios”, o trabalho: considerações em torno de representações sobre o trabalho e a vadiagem no Brasil. Revista Formação. N. 9. V. 2. Presidente Prudente: PPGG-UNESP, 2002, pp. 251-286.

HAESBAERT, Rogério. Des-territorialização e identidade: a rede "gaúcha" no Nordeste. Niterói: EdUFF, 1997.

O Mito da Desterritorialização: do "Fim dos Territórios" à

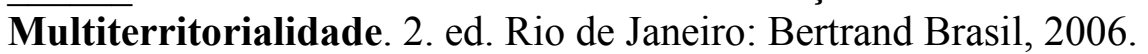

MARTINS, José de Souza. Fronteira: a degradação do Outro nos confins do humano. Hucitec: São Paulo, 1997.

MARTINS, Rubens. Ente jagunços e posseiros. Curitiba, 1986.

MARX, Karl. O Capital: Crítica da Economia Política. Vol. 1. Tomo 1. 2 ed. São Paulo: Nova Cultural, 1985. (Os economistas).

MONDARDO, Marcos L. As Migrações e as Transformações Territoriais na Comunidade Barra do Rio Tuna - Francisco Beltrão - PR. Francisco Beltrão, Paraná, 2005. Monografia (Bacharelado em Geografia) - UNIOESTE. 